\title{
Produção e valor nutritivo da forragem de capim-elefante em dois sistemas de produção
}

\section{Gilmar Roberto Meinerz ${ }^{1}$, Clair Jorge Olivo ${ }^{2}$, Carlos Alberto Agnolin ${ }^{1}$, Ana Paula Dullius ${ }^{3}$, Ricardo da Silveira Moraes ${ }^{3}$, Guilherme Mombach ${ }^{3}$, Vinícius Foletto ${ }^{3}$, Paulo Roberto Machado $^{3}$}

\author{
${ }^{1}$ Curso de Pós-graduação em Zootecnia, Universidade Federal de Santa Maria - UFSM, RS, Brasil. \\ 2 Departamento de Zootecnia - UFSM , RS, Brasil. \\ ${ }^{3}$ Curso de Graduação em Zootecnia - UFSM.
}

RESUMO - Esta pesquisa foi realizada com o objetivo de avaliar a produção e o valor nutritivo da forragem de capimelefante cultivado em sistemas convencional e agroecológico. No sistema convencional, o capim-elefante foi estabelecido em cultivo exclusivo, em linhas com espaçamento de 1,4 m e, no sistema agroecológico, em linhas afastadas 3 m. Nas entrelinhas, estabeleceu-se azevém no período hibernal para desenvolvimento de espécies de crescimento espontâneo no período estival. Avaliaram-se a massa, a produção e a composição botânica e estrutural da forragem e a carga animal. Amostras de simulação de pastejo foram coletadas para determinação dos teores de proteína bruta e fibra em detergente neutro e da digestibilidade in vitro da matéria seca e matéria orgânica. O delineamento experimental foi o inteiramente casualizado com dois tratamentos (sistemas convencional e agroecológico) e duas repetições (piquetes). Valores mais elevados para massa de forragem, produção de forragem, taxa de acúmulo diário e carga animal foram observados no sistema convencional. A relação folha:colmo foi similar entre os sistemas. Valor mais elevado de proteína bruta foi observado no sistema agroecológico. O capim-elefante sob manejo convencional apresenta maior produção de forragem, com menores teores de proteína bruta. O sistema agroecológico apresenta melhor distribuição da produção de forragem no decorrer do ano.

Palavras-chave: agroecologia, bovinos leiteiros, Lolium multiflorum, pastagens consorciadas, Pennisetum purpureum

\section{Forage production and nutritive value of elephantgrass in two production systems}

\begin{abstract}
The objective of this research was to evaluate elephantgrass pasture on forage production and stocking rate, comparing conventional and agro-ecological production systems. In the conventional system, elephantgrass was established in a singular form, in rows spaced by $1.4 \mathrm{~m}$. In the agro-ecological system, the elephantgrass was established spaced by $3 \mathrm{~m}$ and, in the space between lines, ryegrass in cool season was introduced, allowing the development of spontaneous growing species in the warm-season. Herbage mass, forage production, daily accumulation rate of dry matter, botanical and structural composition and stocking rate were evaluated. Hand-plucking samples were collected to determine crude protein, neutra detergent fiber, acid detergent fiber, in vitro digestibility of dry and organic matter. The experimental design was completely randomized, with two treatments (conventional and agro-ecological systems), two replications (paddocks) and repeated measures (grazing cycles). Higher values of herbage mass, forage production, daily accumulation rate of dry matter and stocking rate were observed in the conventional system. Leaf blade/steam ratio was similar between systems. Higher values of crude protein were observed in the agro-ecological system. Elephantgrass in conventional system presents higher forage production with lower values of crude protein. The agro-ecological system presents best forage distribution throughout the year
\end{abstract}

Key Words: agroecology, dairy cattle, intercropped pastures, Lolium multiflorum, Pennisetum purpureum

\section{Introdução}

Em grande parte das propriedades leiteiras, as pastagens são a principal fonte de alimentação dos animais. Nesse contexto, espécies como o capim-elefante (Pennisetum purpureum Schum.), por suas características de alta produção de forragem (Pegoraro et al., 2009) e fácil adaptação a diferentes condições edafoclimáticas, têm grande importância para a produção animal (Alencar, 2002). Sua utilização sob pastejo tem sido crescente no Brasil. Entretanto, há deficiência de informações sobre muitos aspectos envolvidos na sua utilização (Alves et al., 2001). 
Em sua maioria, as pesquisas conduzidas com essa forrageira inserem-se na estratégia convencional de manejo da pastagem (Olivo et al., 2009), caracterizada por cultivo estreme, produção concentrada no período estival e adubação baseada no uso de fertilizantes químicos, especialmente de fonte nitrogenada (Olivo et al., 2006). Essa sistemática pode contribuir, no decorrer do tempo, para a redução da produtividade e perenidade da pastagem (Lima et al., 2004). Estudos para avaliação desta forrageira em sistemas considerados mais sustentáveis são escassos (Olivo et al., 2006).

Pesquisas para avaliação do capim-elefante no decorrer do ano agrícola indicam resultados contraditórios, com algumas apresentando melhor valor nutritivo no período hibernal em comparação ao período estival, embora apresentem menor produção de forragem (Poli, 1992). Devido à sua alta produtividade no período estival e redução do crescimento no período hibernal, o capim-elefante apresenta variações na estrutura e na qualidade da forragem (Townsend et al., 1994).

Assim, realizou-se este estudo com o objetivo de comparar a produção, a composição estrutural e o valor nutritivo do capim-elefante cultivado nos sistemas de produção convencional e agroecológico.

\section{Material e Métodos}

O experimento foi conduzido no Laboratório de Bovinocultura de Leite do Departamento de Zootecnia da Universidade Federal de Santa Maria (UFSM), localizado na região fisiográfica denominada Depressão Central do Rio Grande do Sul, com altitude de 95 m, a $29^{\circ} 43^{\prime}$ de latitude Sul e $53^{\circ} 42$ de longitude Oeste. O solo das áreas experimentais é classificado como Argissolo Vermelho Distrófico Arênico, pertencente à unidade de mapeamento São Pedro (Embrapa, 1999), e o clima da região é o Cfa (subtropical úmido), conforme classificação de Köppen (Moreno, 1961). O delineamento experimental utilizado foi o inteiramente casualizado, com dois tratamentos (sistemas convencional e agroecológico), duas repetições (piquetes) e parcelas subdivididas no tempo (ciclos de pastejo).

O período experimental, compreendido entre maio de 2005 e abril de 2006, totalizou 335 dias. As médias de temperatura e precipitação mensais do período foram de $19,4^{\circ} \mathrm{C}\left(14,72^{\circ} \mathrm{C}\right.$ no período hibernal, entre maio e outubro, e $24,1^{\circ} \mathrm{C}$ no período estival, entre novembro e abril) e 117,4 mm, respectivamente. Os dados foram coletados na Estação Experimental Meteorológica da UFSM, situada a aproximadamente $500 \mathrm{~m}$ da área experimental.
Foram utilizadas duas áreas experimentais, cada uma dividida em dois piquetes de 0,12 ha. As áreas vinham sendo manejadas distintamente, uma no sistema de produção agroecológico, na qual o capim-elefante (Pennisetum purpureum Schum.), cultivar Merckeron Pinda, foi estabelecido em meados de 2001, em linhas afastadas de $3 \mathrm{~m}$, e outra no convencional, com cultivo exclusivo dessa forrageira, em linhas afastadas $1,4 \mathrm{~m}$, constituindo-se nos tratamentos.

No sistema agroecológico, no período hibernal, foi feita a sobressemeadura, em maio, com azevém (Lolium multiflorum Lam.) (40 kg/ha) nas entrelinhas do capimelefante. Para adubação dos pastos nesse sistema, usou-se 150-90-65 kg/ha de $\mathrm{N}-\mathrm{P}_{2} \mathrm{O}_{5}-\mathrm{K}_{2} \mathrm{O}$, com esterco bovino e chorume de suíno, distribuídos no decorrer do ano agrícola (70\% no período estival e 30\% no hibernal). A quantidade de 10,8 t/ha de esterco de bovinos, coletado em mangueira de espera (com 65\% de umidade), correspondeu a 3,75 t de matéria seca (MS) e o volume de $46 \mathrm{~m}^{3} /$ ha de chorume, (com 92\% de umidade), correspondeu a 3,7 t de MS/ha. A composição química desses fertilizantes, com base na MS, foi de 1,2-0,45-0,62 e 2,8-1,9-0,9\% de $\mathrm{N}-\mathrm{P}_{2} \mathrm{O}_{5}-\mathrm{K}_{2} \mathrm{O}$, respectivamente. No sistema convencional, usou-se a mesma quantidade de fertilizante do sistema agroecológico, valendo-se de adubos químicos. Para a adubação nitrogenada, usou-se ureia, distribuída no decorrer dos ciclos de pastejo.

O sistema de pastejo adotado foi o rotacionado, com 2 a 3 dias de ocupação. No sistema convencional, o critério de entrada dos animais na pastagem foi a altura do capimelefante, quando o dossel apresentava cerca de 1,2 m. Esse manejo também foi adotado no sistema agroecológico no período estival. No hibernal, o critério adotado foi a altura do pasto presente na entrelinha (cerca de $20 \mathrm{~cm}$ ). Antecedendo a entrada dos animais, em cada pastejo, foram realizadas amostragens determinando-se a massa de forragem de pré-pastejo, pela técnica de dupla amostragem (Wilm et al., 1944). O capim-elefante foi cortado a $50 \mathrm{~cm}$ do solo. No agroecológico, as espécies presentes na entrelinha foram cortadas rente ao solo. As amostras foram pesadas e homogeneizadas e uma subamostra foi retirada para determinação da composição botânica das pastagens e dos componentes morfológicos do capim-elefante, sendo, posteriormente, seca em estufa de ar forçado a $65^{\circ} \mathrm{C}$ por 72 horas para determinação do teor de matéria seca.

Após a saída dos animais, foi estimada a massa de forragem pós-pastejo, usando-se a mesma metodologia adotada na determinação da massa pré-pastejo. A carga animal foi calculada buscando-se manter uma oferta de $10 \mathrm{~kg}$ de forragem por $100 \mathrm{~kg}$ PV/dia, com base na massa de 
forragem seca inicial. A taxa de acúmulo de forragem foi determinada pela diferença entre a massa de forragem do pré e pós-pastejo e o resultado dividido pelo número de dias entre os ciclos de pastejo (Gerdes et al., 2005). Para o percentual de matéria seca desaparecida, dividiram-se os valores obtidos da diferença entre a massa de forragem no pré e no pós-pastejo pela carga animal, multiplicando-se o resultante por 100 .

Como animais experimentais foram utilizadas vacas da raça Holandesa em lactação, com peso médio de $505 \pm 26$ kg e produção de leite média de 17,3 $\pm 2,8 \mathrm{~kg} / \mathrm{dia}$, recebendo como complemento alimentar, no período hibernal, 1,5 e 3,5 kg/dia de MS de silagem de sorgo e de concentrado, respectivamente. No período estival, os animais receberam $5 \mathrm{~kg}$ de concentrado por dia.

Para estimar o valor nutritivo do capim-elefante, foram coletadas amostras pela técnica de simulação de pastejo (Euclides et al., 1992), após a observação do comportamento ingestivo dos animais por 15 minutos no início e no final de cada pastejo. As amostras foram pesadas, secas em estufa por $72 \mathrm{~h}$ a $65^{\circ} \mathrm{C}$ e posteriormente analisadas no Laboratório de Nutrição Animal (DZ-UFSM) quanto aos conteúdos de PB, pelo método de Kjeldahl (AOAC, 1984), e FDN
(Van Soest et al., 1991), e à digestibilidade in vitro da matéria seca(DIVMS) e da matéria orgânica(DIVMO)(Tilley \& Terry, 1963). Para estimar o NDT das pastagens, foi utilizada a equação: $\mathrm{NDT}=\mathrm{MO}\{[26,8+0,595$ (DIVMO) $] / 100\}$, descrita por Kunkle \& Bates (1998), na qual NDT refere-se aos nutrientes digestíveis totais (\%); MO à matéria orgânica (\%); e DIVMO à digestibilidade in vitro da matéria orgânica (\%).

Os dados coletados foram submetidos à análise de variância e as médias comparadas pelo teste $\mathrm{F}$, a 5\% de significância. Também foram feitas análises de correlação, pelo coeficiente de Pearson e de regressão, em função dos ciclos de pastejo. As análises foram conduzidas com auxílio do pacote estatístico SAS (1997).

\section{Resultados e Discussão}

Durante o período experimental, foram conduzidos oito ciclos de pastejo no sistema agroecológico (Tabela 1), quatro em cada período (hibernal e estival), com intervalo médio de 36 e 41 dias, respectivamente. No sistema convencional, foram feitos sete pastejos, com intervalo médio de 41 dias em cada ciclo, semelhante ao agroecológico no período estival. Analisando-se a duração dos ciclos de

Tabela 1 - Massa de forragem total e do capim-elefante (kg/ha de MS), percentuais dos componentes morfológicos e biomassa de lâminas foliares de capim-elefante ao pré e pós-pastejo nos sistemas de produção agroecológico e convencional

\begin{tabular}{|c|c|c|c|c|c|c|c|c|c|c|c|}
\hline \multirow[t]{2}{*}{ Parâmetro } & \multirow[t]{2}{*}{ Sistema } & \multicolumn{8}{|c|}{ Pastejo } & \multirow[t]{2}{*}{ Média } & \multirow[t]{2}{*}{ CV (\%) } \\
\hline & & $\begin{array}{c}1 \stackrel{0}{\circ} \\
(j u l / 05)\end{array}$ & $\begin{array}{c}2 \stackrel{0}{ } \\
(\text { ago/05) }\end{array}$ & $\begin{array}{c}3 \stackrel{o}{0} \\
\text { (set/05) }\end{array}$ & $\begin{array}{c}4 \stackrel{\text { o }}{ } \\
\text { (out } / 05)\end{array}$ & $\begin{array}{c}5 \underline{0} \\
(\operatorname{dez} / 05)\end{array}$ & $\begin{array}{c}6^{0} \\
(j a n / 06)\end{array}$ & $\begin{array}{c}7 \underline{0} \\
(\operatorname{mar} / 06)\end{array}$ & $\begin{array}{c}8^{\circ} \underline{0} \\
(a b r / 06)\end{array}$ & & \\
\hline \multicolumn{12}{|c|}{ Pré-pastejo } \\
\hline \multirow[t]{2}{*}{ Massa de forragem total (kg/ha) } & Agroecológico & 3591 & 3557 & 3190 & 3898b & 3919 & 4675 b & $5252 b$ & $4743 b$ & 4096 & 17,18 \\
\hline & Convencional & 4401 & 4712 & - & $6522 \mathrm{a}$ & 5472 & $8796 a$ & 10069a & 7998a & 6074 & \\
\hline \multirow{2}{*}{$\begin{array}{l}\text { Massa de forragem do } \\
\text { capim-elefante (kg/ha) }\end{array}$} & Agroecológico & 2824 & 2632 & 2282 & 2170b & 2701 & 3193 b & $3731 b$ & $3351 b$ & 2860 & 19,30 \\
\hline & Convencional & 4401 & 4712 & - & $6522 a$ & 5472 & $8796 a$ & $1069 a$ & 7998a & 6074 & \\
\hline \multirow{2}{*}{$\begin{array}{l}\text { Biomassa de lâminas foliares do } \\
\text { capim-elefante }(\mathrm{kg} / \mathrm{ha})\end{array}$} & Agroecológico & 837 & $662 b$ & 375 & $620 \mathrm{~b}$ & 1001 & $1719 b$ & $1634 b$ & $1408 b$ & 987 & 16,32 \\
\hline & Convencional & 1087 & $1328 a$ & - & $2604 a$ & 2652 & $5897 a$ & 3603a & $2025 a$ & 2396 & \\
\hline \multirow[t]{2}{*}{ Lâminas foliares do capim-elefante (\%) } & Agroecológico & 29,92 & 25,37 & 16,47 & 28,94 & 37,02 & 54,38 & $44,01 \mathrm{a}$ & 31,32 & 33,45 & 10,44 \\
\hline & Convencional & 24,76 & 28,48 & - & 39,94 & 47,8 & 67,16 & $33,69 b$ & 25,62 & 33,39 & \\
\hline \multirow[t]{2}{*}{ Colmos capim-elefante (\%) } & Agroecológico & 61,19 & 55,02 & 64,08 & 55,13 & 48,8 & 36,26 & 37,04 & 14,01 & 48,06 & 21,53 \\
\hline & Convencional & 54,44 & 56,19 & - & 49,56 & 43,15 & 32,83 & 52,71 & 17,99 & 43,19 & \\
\hline \multirow[t]{2}{*}{ Material morto do capim-elefante (\%) } & Agroecológico & 8,87 & 19,58 & 19,42 & 15,91 & 13,9 & $9,29 a$ & 10,56 & 14,01 & 13,94 & 25,17 \\
\hline & Convencional & 20,77 & 15,31 & - & 10,48 & 9,0 & $1,0 \mathrm{~b}$ & 13,58 & 17,99 & 10,89 & \\
\hline \multicolumn{12}{|c|}{ Pós-pastejo } \\
\hline \multirow[t]{2}{*}{ Massa de forragem total $(\mathrm{kg} / \mathrm{ha})$} & Agroecológico & 2487 & 2636 & 2495 & 3037 & 3090 & $3368 b$ & $3774 b$ & $3436 b$ & 3028 & 17,34 \\
\hline & Convencional & 3345 & 3481 & - & 4920 & 4300 & $7225 a$ & 7823a & 5582a & 4588 & \\
\hline \multirow{2}{*}{$\begin{array}{l}\text { Massa de forragem do } \\
\text { capim-elefante (kg/ha) }\end{array}$} & Agroecológico & 1955 & 2186 & 1858 & 1936 & 1670 & 3193b & $2675 b$ & $3351 b$ & 2490 & 18,57 \\
\hline & Convencional & 3345 & 3481 & - & 4920 & 4300 & $7255 a$ & 7823a & 5582a & 4588 & \\
\hline \multirow{2}{*}{$\begin{array}{l}\text { Biomassa de lâminas foliares } \\
\text { do capim-elefante }(\mathrm{kg} / \mathrm{ha})\end{array}$} & Agroecológico & 189 & 228 & 210 & $328 b$ & $310 \mathrm{~b}$ & $1168 b$ & 595 & 357 & 423 & 24,31 \\
\hline & Convencional & 484 & 528 & - & $942 a$ & $1373 a$ & $2327 a$ & 932 & 484 & 884 & \\
\hline \multirow[t]{2}{*}{ Lâminas foliares do capim-elefante (\%) } & Agroecológico & $9,71 b$ & 10,34 & 11,16 & 16,97 & 18,83 & 36,84 & 15,77 & 10,68 & 16,29 & 10,81 \\
\hline & Convencional & $14,89 a$ & 15,38 & - & 19,20 & 31,79 & 32,06 & 11,92 & 8,55 & 16,72 & \\
\hline \multirow[t]{2}{*}{ Colmos capim-elefante (\%) } & Agroecológico & 70,78 & 71,62 & 65,25 & 67,00 & 68,66 & 49,85b & 71,46 & 65,26 & 66,23 & 9,40 \\
\hline & Convencional & 66,59 & 70,67 & - & 62,40 & 54,69 & $67,93 a$ & 47,95 & 73,85 & 58,88 & \\
\hline \multirow{2}{*}{ Material morto do capim-elefante (\%) } & Agroecológico & 19,50 & 18,01 & 23,56 & 16,01 & 12,50 & $13,28 a$ & 12,74 & 24,01 & 17,45 & 37,68 \\
\hline & Convencional & 18,51 & 13,94 & - & 18,38 & 13,50 & $2,0 \mathrm{~b}$ & 13,11 & 17,57 & 11,87 & \\
\hline
\end{tabular}

$\mathrm{a}, \mathrm{b}=$ médias seguidas por letras distintas na coluna diferem $(\mathrm{P}<0,05)$ entre si. 
pastejo, considera-se que tempos de ocupação de 2 a 3 dias, associados a períodos de descanso de 30 dias, estão relacionados à melhor qualidade da forragem e ao maior desempenho animal (Deresz et al., 2001; Soares et al., 2004). Os ciclos mais longos verificados no período estival devem-se à deficiência hídrica, que foi de $29 \%$, em relação à média climática.

No sistema convencional (Tabela 1), constituído basicamente por capim-elefante, a pastagem foi utilizada em parte do período hibernal, devido às temperaturas mais elevadas observadas no período, que foram em média de $1,4^{\circ} \mathrm{C}$ superior à média climática, de $14,72^{\circ} \mathrm{C}$, além do menor número de geadas, que ocorreram tardiamente (a primeira verificada em junho). Essa condição permitiu o desenvolvimento do capim-elefante no período hibernal e também influenciou a composição da pastagem do sistema agroecológico, mantendo elevada sua participação. Sob condições próximas da normalidade climática, Sobczack et al. (2005), trabalhando com a referida cultivar de capim-elefante sob manejo de transição agroecológica na mesma região, em pastejos efetuados em junho, agosto e setembro, observaram porcentagens de lâminas foliares de 13,7; 1,7 e 6,5\%, sendo menores que as verificadas neste trabalho (Tabela 1).

No sistema agroecológico, a massa de forragem no período hibernal variou de 3 a 4 t/ha e a participação do capim-elefante, ocupando $25 \%$ da área, foi de 2 t/ha, aproximadamente. Essa contribuição foi expressiva nesse período, devido à temperatura mais elevada e ao menor número de geadas, mantendo elevada a biomassa de lâminas foliares no inverno (Tabela 1).

Na entrelinha, a massa de forragem média foi constituída especialmente por azevém (45\%) e capim-forquilha (Paspalum conjugatum), com 25\%, para os pastejos efetuados entre julho e outubro. Os demais componentes da pastagem foram constituídos por gervão (Stachytarpheta cayennensis), roseta (Soliva pterosperma), outras plantas e material morto, com 6,0; 2,0; 9,0 e 5,8\%, respectivamente (Tabela 2).

No período estival, houve aumento da massa de forragem, em razão da maior contribuição do capim-elefante e das espécies de crescimento espontâneo presentes na entrelinha, constituídas especialmente por capim-forquilha (48,31\%), guanxuma (Sida sp.) (37,90\%), gervão (3,88\%), outras plantas $(5,24 \%)$ e material morto $(10,28 \%)$, como média dos pastejos efetuados entre dezembro e abril. Essas espécies também foram relatadas por Olivo et al. (2009) em estudo com pastagens de capim-elefante consorciadas com azevém, espécies de crescimento espontâneo e amendoimforrageiro ou trevo-branco.

No sistema convencional, a massa de forragem total, constituída basicamente por capim-elefante, foi superior $(\mathrm{P}<0,05)$ à verificada no agroecológico. As condições meteorológicas atípicas no período hibernal propiciaram condições para o crescimento do capim-elefante (Tabela 2), proporcionando pastejo em agosto que, sob condições climáticas normais para a região, apresenta porcentagem de lâminas foliares inferior a 2\% (Olivo et al., 2006). No período

Tabela 2 - Massa de forragem total das espécies presentes na entrelinha, em kg/ha, no pré e pós-pastejo de pastagens de capim-elefante em sistemas agroecológico e convencional

\begin{tabular}{|c|c|c|c|c|c|c|c|c|}
\hline \multirow[t]{2}{*}{ Parâmetro } & \multicolumn{8}{|c|}{ Pastejo } \\
\hline & $\begin{array}{c}1 \underline{\mathrm{o}} \\
\text { (jul/05) }\end{array}$ & $\begin{array}{c}2 \underline{\mathrm{o}} \\
\text { (ago/05) }\end{array}$ & $\begin{array}{c}3 \underline{0} \\
\text { (set/05) }\end{array}$ & $\begin{array}{c}4 \underline{\mathrm{o}} \\
\text { (out/05) }\end{array}$ & $\begin{array}{c}5 \underline{0} \\
(\mathrm{dez} / 05)\end{array}$ & $\begin{array}{c}6 \underline{\mathrm{o}} \\
(\mathrm{jan} / 06)\end{array}$ & $\begin{array}{c}7 \underline{0} \\
(\mathrm{mar} / 06)\end{array}$ & $\begin{array}{c}8 \underline{0} \\
(\mathrm{abr} / 06)\end{array}$ \\
\hline & \multicolumn{8}{|c|}{ Pré-pastejo } \\
\hline Massa de forragem das espécies na entrelinha & 900 & 1050 & 1050 & 1612 & 1850 & 2250 & 1687 & 1590 \\
\hline Azevém & 54 & 598 & 707 & 1136 & 0 & 0 & 0 & 0 \\
\hline Paspalum & 552 & 247 & 113 & 104 & 555 & 1062 & 1096 & 853 \\
\hline Roseta & 30 & 14 & 10 & 40 & 0 & 0 & 0 & 0 \\
\hline Guanxuma & 0 & 0 & 0 & 0 & 222 & 137 & 253 & 87 \\
\hline Gervão & 108 & 31 & 77 & 64 & 20,35 & 112 & 67 & 86 \\
\hline Outras & 126 & 100 & 77 & 112 & 74 & 180 & 101 & 31 \\
\hline \multirow[t]{2}{*}{ Material morto } & 108 & 68 & 47 & 48 & 107 & 193 & 118 & 340 \\
\hline & \multicolumn{8}{|c|}{ Pós-pastejo } \\
\hline Massa de forragem das espécies na entrelinha & 527 & 635 & 665 & 1300 & 962 & 990 & 910 & 813 \\
\hline Azevém & 42 & 165 & 365 & 715 & 0 & 0 & 0 & 0 \\
\hline Paspalum & 173 & 235 & 109 & 78 & 365 & 623 & 561 & 287 \\
\hline Roseta & 10 & 6 & 6 & 13 & 0 & 0 & 0 & 0 \\
\hline Guanxuma & 0 & 0 & 0 & 0 & 185 & 69 & 136 & 87 \\
\hline Gervão & 84 & 30 & 0 & 91 & 16 & 29 & 45 & 87 \\
\hline Outras & 152 & 95 & 136 & 195 & 48 & 29 & 45 & 33 \\
\hline Material morto & 63 & 102 & 66 & 208 & 346 & 228 & 121 & 308 \\
\hline
\end{tabular}

Pastagem sob sistema agroecológico = capim-elefante $(\mathrm{CE})$ + azevém + espécies de crescimento espontâneo (ECE) no período hibernal; CE + ECE no período estival. Paspalum = Paspalum conjugatum; Roseta = Soliva pterosperma , gervão = Stachytarpheta cayennensis; guanxuma = Sida santaremnensis . 
hibernal, esse componente estrutural apresentou valor superior a $24 \%$. No decorrer da avaliação, o capim-elefante apresentou comportamento típico, com ápice da produção no final da primavera e durante o verão, condição que pode ser visualizada pela maior biomassa de lâminas foliares verificada nesse período (Tabela 1 ).

Os resultados do material de pós-pastejo comprovam comportamento semelhante ao das variáveis de pré-pastejo. O capim-elefante foi consumido de forma similar $(\mathrm{P}>0,05)$ nos dois sistemas, considerando os valores porcentuais de pré e pós-pastejo da porcentagem de lâminas foliares.

Para a taxa de desaparecimento da matéria seca, considerando as médias dos pastejos em ambas as pastagens, o valor foi de $25 \%$ da massa de forragem inicial aproximadamente. Para as massas de forragem total e de lâminas foliares do capim-elefante, as taxas foram de 12,$93 ; 57,04$ e 24,$46 ; 63,31 \%$, para os pastos sob manejo agroecológico e convencional, respectivamente. As taxas de desaparecimento das frações correspondentes ao capimelefante são menores no sistema agroecológico. Esse resultado deve-se, possivelmente, à presença das demais espécies nessa pastagem, permitindo, assim, condições para os animais selecionarem as espécies para sua dieta. Entre elas, destaca-se o azevém, que apresentou taxa média de desaparecimento de $45 \%$. No capim-forquilha, os apresentou valores médios foram de 25 e $28 \%$ nos períodos hibernal e estival, respectivamente. Mesmo espécies nãoforrageiras, como a guanxuma, com $28 \%$, e o gervão, com 20 e 31\% (para os respectivos períodos), confirmam a seletividade dos animais.

A relação entre lâminas foliares e colmos (Figura 1) do capim-elefante foi similar $(\mathrm{P}>0,05)$ entre os sistemas forrageiros. A análise de regressão sobre o comportamento dessa variável no decorrer dos pastejos comprovou que o modelo que melhor se ajustou foi o polinomial cúbico, para ambas as pastagens (Figura 1). No período estival, os valores médios da relação lâminas foliares/colmo+bainha para os pastejos efetuados entre dezembro e abril foram de 0,92 e 1,08 e, no período hibernal, os valores foram de 0,56 e 0,66 para os sistemas agroecológico e convencional, respectivamente. Valores próximos aos encontrados neste trabalho no período estival foram relatados por Hillesheim (1987) e Fonseca et al. (1998) em pesquisa com a cultivar Napier no período das águas com períodos de descanso de 31 a 67 dias e períodos de ocupação de cinco dias.

O maior valor (próximo a dois, no sistema convencional) foi observado no pastejo realizado em janeiro, período de maior crescimento do capim-elefante, superior $(\mathrm{P}<0,05)$ ao sistema agroecológico. Essa diferença provavelmente se deve à utilização da ureia como fonte de nitrogênio, que apresenta liberação mais rápida desse elemento, proporcionando maior crescimento da planta se comparada ao esterco bovino e ao chorume suíno utilizados na pastagem agroecológica.

O valor médio de MS desaparecida foi maior $(\mathrm{P}<0,05)$ no sistema agroecológico (Tabela 3) e foi ocasionado pela maior perda de forragem nessa pastagem, devido ao pisoteio dos animais nas espécies presentes na entrelinha, que, por apresentarem menor porte, sofrem maior impacto em comparação à estrutura mais ereta do capim-elefante no sistema convencional. Nessa condição, as perdas são menores, uma vez que os animais caminham em meio às touceiras do capim-elefante (Pegoraro et al., 2009).

Para taxa de acúmulo diário de MS (Tabela 3) no sistema convencional, verificou-se grande variação no decorrer do ano: a menor ocorreu em agosto e a maior em dezembro. Em trabalho conduzido na mesma região com a cultivar Taiwan, Missio et al. (2006) obtiveram taxas menores, variando de 50,8 a 119,4 kg de MS/ha entre janeiro e março. Taxas mais uniformes, entre 64,0 e 78,2 kg de MS/ha, foram obtidas no

Relação lâmina foliar/colmo+bainha

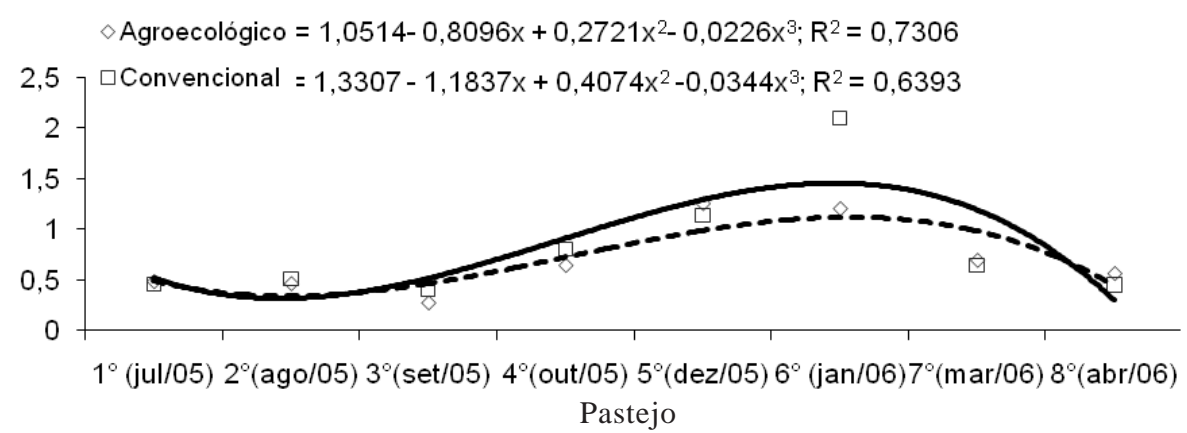

Figura 1 - Relação folha/colmo do capim-elefante em sistemas de produção agroecológico e convencional. 
período das águas por Carvalho et al. (2005) em pesquisa com a cultivar Napier. Entre épocas do ano, Paciullo et al. (2003) também verificaram grande variabilidade, com taxas de acúmulo entre 8,9 e 125,6 kg MS/ha para os períodos de julho-agosto e fevereiro-março, respectivamente.

No sistema convencional, $85,65 \%$ da forragem foi acumulada sob forma de lâminas foliares do capim-elefante, enquanto no agroecológico esse valor foi de 53,31\%. A carga animal apresentou diferenças $(\mathrm{P}<0,05)$ entre os pastejos efetuados nos meses de outubro, janeiro e março, com valores mais elevados no sistema convencional. As cargas médias referentes aos períodos hibernal e estival foram de 829 e 1153; 948 e $2160 \mathrm{~kg} / \mathrm{ha} /$ dia para os sistemas agroecológico e convencional. Lotações similares às obtidas no período estival, no convencional, entre 4 e 4,5 vacas/ha, foram observadas por Deresz et al. (2001).

Em média, o teor de FDN não diferiu $(\mathrm{P}>0,05)$ entre as pastagens (Tabela 4), mas foi menor no período hibernal. Ressalta-se que os teores obtidos em capim-elefante, nessa época, são similares aos de gramíneas anuais de ciclo hibernal, como os encontrados por Ballocchi et al. (2002), que obtiveram valor médio de $49,16 \%$ em pastagens constituídas basicamente por azevém. Os maiores teores de FDN verificados no período estival podem estar associados ao aumento na lignificação da parede celular e à maior atividade metabólica da planta, que converte

Tabela 3 - Carga animal instantânea, matéria seca desaparecida e taxa de acúmulo diário de forragem em pastagens submetidas aos sistemas de produção agroecológico e convencional

\begin{tabular}{|c|c|c|c|c|c|c|c|c|c|c|}
\hline \multirow[t]{2}{*}{ Sistema de produção } & \multicolumn{8}{|c|}{ Pastejo } & \multirow[t]{2}{*}{ Total/média } & \multirow[t]{2}{*}{ CV (\%) } \\
\hline & $\begin{array}{c}1 \underline{0} \\
(j u l / 05)\end{array}$ & $\begin{array}{c}2 \underline{0} \\
(\text { ago/05) }\end{array}$ & $\begin{array}{c}3 \underline{o} \\
(\text { set/05) }\end{array}$ & $\begin{array}{c}4 \underline{\text { o }} \\
\text { (out/05) }\end{array}$ & $\begin{array}{c}5 \underline{0} \\
(\operatorname{dez} / 05)\end{array}$ & $\begin{array}{c}6 \underline{0} \\
(\mathrm{jan} / 06)\end{array}$ & $\begin{array}{c}7 \underline{0} \\
(\operatorname{mar} / 06)\end{array}$ & $\begin{array}{c}8 \underline{0} \\
(\mathrm{abr} / 06)\end{array}$ & & \\
\hline \multicolumn{11}{|c|}{ Produção de forragem (kg/ha de MS) } \\
\hline Agroecológico & 1104 & 1070 & 554 & $1403 b$ & 882 & $1585 b$ & $1884 b$ & $969 a$ & 9451 & 17,64 \\
\hline Convencional & 1056 & 1367 & - & $3041 \mathrm{a}$ & 552 & $4496 a$ & $3470 \mathrm{a}$ & $175 b$ & 12790 & \\
\hline \multicolumn{11}{|c|}{ Produção de Biomassa de lâminas foliares (kg/ha de MS) } \\
\hline Agroecológico & 648 & $473 b$ & 147 & $410 \mathrm{~b}$ & $673 b$ & $1409 b$ & $466 \mathrm{~b}$ & 813 & 5039 & 22,17 \\
\hline Convencional & 603 & $844 a$ & - & $2076 a$ & $1710 \mathrm{a}$ & $4524 a$ & $1276 a$ & 1093 & 12126 & \\
\hline \multicolumn{11}{|c|}{ Carga animal instantânea (kg de peso vivo/ha) } \\
\hline Agroecológico & 37803 & 29853 & 34000 & $40000 b$ & 37400 & $47350 b$ & $56533 b$ & 48560 & 41062 & 15,03 \\
\hline Convencional & 49524 & 47932 & - & $64762 \mathrm{a}$ & 54421 & $91700 \mathrm{a}$ & 106217a & 72925 & 60935 & \\
\hline \multicolumn{11}{|c|}{ Matéria seca desaparecida (\% do peso vivo) } \\
\hline Agroecológico & 2,94 & 2,56 & 2,23 & 2,33 & 2,31 & 2,57 & 3,15 & 2,92 & 2,63 & 6,17 \\
\hline Convencional & 2,34 & 2,50 & - & 2,52 & 2,15 & 3,00 & 2,59 & 2,47 & 2,19 & \\
\hline \multicolumn{11}{|c|}{ Taxa de acúmulo diário (kg de MS/dia) } \\
\hline Agroecológico & - & $21,42 \mathrm{a}$ & $64,86 a$ & $50,11 \mathrm{a}$ & $17,60 \mathrm{~b}$ & $38,22 b$ & 47,11 & 26,04 & 31,19 & 24,07 \\
\hline Convencional & - & $6,75 b$ & $10,70 \mathrm{~b}$ & $10,70 \mathrm{~b}$ & $60,83 a$ & $149,86 a$ & 61,44 & 14,07 & 49,39 & \\
\hline
\end{tabular}

$\mathrm{a}, \mathrm{b}=$ médias seguidas por letras distintas na coluna diferem $(\mathrm{P}<0,05)$ entre si.

Tabela 4 - Percentuais de fibra em detergente neutro (FDN), proteína bruta (PB), matéria orgânica (MO) e nutrientes digestíveis totais (NDT) e digestibilidade in vitro da matéria seca (DIVMS) e matéria orgânica (DIVMO) de pastos de capim-elefante em sistemas de produção agroecológico (SFA) e convencional (SFC)

\begin{tabular}{|c|c|c|c|c|c|c|c|c|c|c|c|}
\hline \multirow[t]{2}{*}{ Parâmetro } & \multirow[t]{2}{*}{ Sistema de produção } & \multicolumn{8}{|c|}{ Pastejo } & \multirow[t]{2}{*}{ Média } & \multirow[t]{2}{*}{$\mathrm{CV}(\%)$} \\
\hline & & $\begin{array}{c}1 \underline{0} \\
\text { (jul/05) }\end{array}$ & $\begin{array}{c}2 \underline{\mathrm{o}} \\
\text { (ago/05) }\end{array}$ & $\begin{array}{c}3^{0} \underline{0} \\
\text { (set/05) }\end{array}$ & $\begin{array}{c}4 \underline{\mathrm{o}} \\
\text { (out/05) }\end{array}$ & $\begin{array}{c}5 \underline{\text { o }} \\
(\mathrm{dez} / 05)\end{array}$ & $\begin{array}{c}6 \underline{0} \\
(\mathrm{jan} / 06)\end{array}$ & $\begin{array}{c}7 \underline{0} \\
(\operatorname{mar} / 06)\end{array}$ & $\begin{array}{c}8 \underline{0} \\
(\mathrm{abr} / 06)\end{array}$ & & \\
\hline \multirow[t]{2}{*}{ Fibra em detergente nuetro } & Agroecológico & 45,72 & 50,12 & 46,44 & 50,14 & 50,75 & 51,65 & 55,12 & 50,82 & 50,32 & 6,94 \\
\hline & Convencional & 50,00 & 46,6 & - & 51,72 & 54,47 & 52,09 & 54,48 & 51,02 & 51,42 & \\
\hline \multirow{2}{*}{ Proteína bruta } & Agroecológico & 17,49 & 18,54 & 20,17 & 15,12 & 12,54 & 15,14 & 10,96 & 15,24 & 15,24 & 7,53 \\
\hline & Convencional & 17,16 & 16,42 & - & 13,36 & 11,74 & 13,34 & 12,07 & 11,86 & 13,99 & \\
\hline \multirow[t]{2}{*}{ DIVMS } & Agroecológico & $70,26 a$ & 73,40 & 70,87 & 68,36 & 65,65 & 68,71 & 64,24 & 68,78 & 68,78 & 5,51 \\
\hline & Convencional & $65,37 b$ & 68,66 & - & 67,72 & 64,97 & 65,09 & 66,33 & 68,89 & 66,96 & \\
\hline \multirow[t]{2}{*}{ Matéria orgânica } & Agroecológico & 85,52 & 86,24 & 85,29 & $85,76 b$ & 89,36 & $88,99 b$ & 90,83 & 87,40 & 87,40 & 0,59 \\
\hline & Convencional & 86,24 & 86,00 & - & $89,30 a$ & 89,54 & $90,99 a$ & 91,66 & 89,30 & 89,21 & \\
\hline \multirow[t]{2}{*}{ DIVMO } & Agroecológico & 72,37 & 73,93 & 76,15 & 70,32 & 67,87 & 70,47 & 66,40 & 70,51 & 70,51 & 5,14 \\
\hline & Convencional & 66,88 & 70,46 & - & 69,50 & 66,93 & 67,29 & 68,42 & 72,24 & 68,82 & \\
\hline \multirow[t]{2}{*}{ Nutrientes digestíveis totais } & Agroecológico & $59,77 a$ & 61,75 & 59,88 & 58,87 & 59,57 & 60,88 & 59,45 & 59,68 & 59,68 & 3,50 \\
\hline & Convencional & $57,62 b$ & 59,17 & - & 60,62 & 60,09 & 60,13 & 61,05 & 61,96 & 60,07 & \\
\hline
\end{tabular}

$\mathrm{a}, \mathrm{b}=$ médias seguidas por letras distintas na coluna diferem $(\mathrm{P}<0,05)$ entre si. 
mais rapidamente o conteúdo celular em compostos estruturais (Van Soest, 1994). Valores de FDN superiores aos encontrados neste trabalho foram obtidos por Soares et al. (2004), entre 64,1 e 69,2\%, em pastagens de capimelefante, cultivar Napier, sob manejo rotacionado na estação chuvosa.

A análise de regressão para a PB comprovou efeito cúbico com início ascendente $(\mathrm{y}=12,617+6,8469 \mathrm{x}-$ $\left.2,1337 x^{2}+0,1644 x^{3} ; R^{2}=0,73\right)$, demonstrando que os teores foram maiores no período hibernal, em decorrência do menor crescimento do capim-elefante nessa época. A correlação inversa encontrada entre fotoperíodo e o teor de $\mathrm{PB}(\mathrm{r}=-0,75 ; \mathrm{P}=0,002)$ confirma essa associação. No sistema convencional, verificou-se efeito cúbico para o teor de PB, com início descendente $\left(\mathrm{y}=20,73-3,65 \mathrm{x}+0,5248 \mathrm{x}^{2}-\right.$ $\left.0,0258 \mathrm{x}^{3} ; \mathrm{R}^{2}=0,87\right)$, também com menores valores no período estival. Associação inversa, normalmente esperada, foi encontrada entre a PB e a $\mathrm{MO}(\mathrm{r}=-0,83 ; \mathrm{P}=0,0002)$. Segundo Poli (1992), com o desenvolvimento da planta e a consequente elevação dos teores de MS, parede celular, celulose, fibra e lignina, diminuem os teores de PB. Esse comportamento é mais acentuado no verão, época em que o crescimento das plantas tropicais é mais intenso.

Os valores médios observados são superiores aos encontrados por Townsend et al. (1994), em uma sequência de três avaliações, de novembro a março, na região central do Rio Grande do Sul, com teores de PB de 8,9; 11,0 e 10,9\%, também em amostras de pastejo simulado e trabalhando com a mesma cultivar. Resultado similar ao deste trabalho, entre 14 e 15\%, foi observado por Lopes et al. (2005) na cultivar Napier sob condições de irrigação e diferentes doses de adubação no decorrer de um ano.

Os teores de matéria orgânica no decorrer dos ciclos de pastejo foram mais elevados no período estival, especialmente no sistema convencional. Possivelmente esse resultado deve-se às características de dossel dessa pastagem, implicando em menor interceptação de luz e menor teor de matéria mineral, consequentemente (Bueno et al., 2003), se comparado ao sistema agroecológico. A diferença no conteúdo de matéria orgânica não se refletiu $(\mathrm{P}>0,05)$ na DIVMO e no NDT dos pastos. No decorrer da utilização, melhores resultados foram observados no período hibernal para essas variáveis, com teores mais elevados no sistema agroecológico no mês de julho. Rodrigues et al. (2001) observaram teor médio menor, de $44,47 \%$ de NDT, para silagem de capim-elefante confeccionada com a cultivar Napier cortada aos 75 dias. $\mathrm{O}$ valor médio obtido, próximo a $60 \%$, é superior ao normalmente esperado para essa forrageira, de 55\% (NRC, 1989).
A digestibilidade in vitro da matéria seca (DIVMS) não apresentou diferenças $(\mathrm{P}<0,05)$ entre as pastagens. Os valores sofreram baixa variação no decorrer do ano agrícola, mantendo-se entre 66,4 e 72,4\%. Deresz et al. (2006) verificaram teor médio de $63,8 \%$ em pastagens de capim-elefante adubada com $200 \mathrm{~kg} / \mathrm{ha} / \mathrm{ano}$ de $\mathrm{N}$ na estação da águas em pastejo com bovinos leiteiros.

Não foram observadas associações entre os valores da relação lâmina foliar/colmo+bainha com as variáveis de valor nutritivo, indicando que o critério de utilização do capim-elefante deve ter como base a oferta de lâminas foliares. Esta forma de manejo pode permitir a manutenção de um resíduo de lâminas foliares pós-pastejo mais uniforme, favorecendo o rebrote do capim-elefante.

\section{Conclusões}

Os valores de massa de forragem e de carga animal no sistema convencional são mais altos que no sistema agroecológico, todavia, no sistema agroecológico, a distribuição da forragem no decorrer do ano agrícola é mais uniforme. O valor nutritivo da forragem de capimelefante em pastejo está associado à relação lâmina foliar/colmo+bainha. A utilização do capim-elefante sob pastejo rotacionado em sistemas de produção convencional ou agroecológico pode ser uma estratégia importante de alimentação de bovinos na Região Sul do Brasil, uma vez que, no período hibernal, há melhoria de sua qualidade, embora ocorra diminuição da forragem produzida.

\section{Referências}

ALENCAR, C.A.B. Resultados obtidos em fazendas produtoras de leite em pastagens manejadas intensivamente. In: MARTINS, C.E.; CÓSER, A.C.; YAMAGUCHI, L.C.T. et al. (Eds.) Gestão estratégica para o desenvolvimento da pecuária leiteira na região Campo das Vertentes. Juiz de Fora: Embrapa CNPGL/Cemig, 2002. p.98-122.

ALVES, G.R.; FONTES, C.A.A.; ERBESDOBLER, E.D. et al. Influência do nível de consumo de pasto de capim-elefante sobre a composição da digesta e concentração do indicador $\mathrm{Cr}_{2} \mathrm{O}_{3}$ no trato gastrintestinal de bovinos. Revista Brasileira de Zootecnia, v.30, n.6, p.2110-2120, 2001 (supl.).

AROEIRA, L.J.M.; LOPES, F.C.F.; DERESZ, F. et al. Pasture availability and dry matter intake of lactating crossbred cows grazing elephantgrass (Pennisetum purpureum Schum). Animal Feed Science and Technology, v.78, n.1, p.313-324, 1999.

ASSOCIATION OF OFFICIAL ANALYTICAL CHEMISTS AOAC. Official methods of analysis. 14.ed. Arlington, 1984. $1094 p$.

BALOCCHI, O.; PULIDO, R.; FÉRNANDEZ, J. Comportamiento de vacas lecheras en pastoreo com y sin suplementación com concentrado. Agricultura Técnica, v.62, n.1, p.87-98, 2002.

BUENO, A.A.O. Características estruturais do dossel forrageiro, valor nutritivo e produção de forragem em pastos de capimmombaça submetidos a regimes de lotação intermitente. 
2003. 76f. Dissertação (Mestrado em Agronomia) - Escola Superior de Agricultura Luiz de Queiroz/Universidade de São Paulo, Piracicaba.

CARVALHO, C.A.B.; PACIULLO, D.S.C.; ROSSIELLO, R.O.P. et al. Morfogênese do capim-elefante manejado sob duas alturas de resíduo pós-pastejo. Boletim da Indústria Animal, v.62, n.2, p.101-109, 2005.

DALL'AGNOL, M.; SCHEFFER-BASSO, S.M.; NASCIMENTO, J.A.L. et al. Produção de forragem de capim-elefante sob clima frio. Curva de crescimento e valor nutritivo. Revista Brasileira de Zootecnia, v.33, n.5, p.1110-1117, 2004.

DERESZ, F.; LOPES, F.C.F.; AROEIRA, L.J.M. Produção de leite de vacas mestiças holandês x zebu em pastagem de capimelefante, com e sem suplementação durante a época das chuvas. Arquivo Brasileiro de Medicina Veterinária e Zootecnia, v.55, n.3, p.334-340, 2001.

DERESZ, F.; PAIM-COSTA, M.L.; CÓSER, A.C. et al. Composição química, digestibilidade e disponibilidade de capim-elefante cv. Napier manejado sob pastejo rotativo. Revista Brasileira de Zootecnia, v.35, n.3, p.863-869, 2006.

EMPRESA BRASILEIRA DE PESQUISA AGROPECUÁRIA EMBRAPA. Centro Nacional de Pesquisa Agropecuária. Sistema brasileiro de classificação de solos. Brasília: EMBRAPA, 1999. 412p

EUCLIDES, V.P.B.; MACEDO, M.C.M.; OLIVEIRA, M.P. Avaliação de diferentes métodos de amostragens sob pastejo. Revista Brasileira de Zootecnia, v.21, n.5, p.691-702, 1992.

FONSECA, D.M.; SALGADO, L.T.; QUEIROZ, D.S. et al. Produção de leite em pastagem de capim-elefante sob diferentes períodos de ocupação dos piquetes. Revista Brasileira de Zootecnia, v.27, n.5, p.848-856, 1998.

GERDES, L.; MATTOS, H. B.; WERNER, J.C. et al. Características do dossel forrageiro e acúmulo de forragem em pastagem irrigada de capim-aruana exclusivo ou sobre-semeado com uma mistura de espécies forrageiras de inverno. Revista Brasileira de Zootecnia, v.34, n.4, p.1088-1097, 2005

HILLESHEIM, A. Fatores que afetam o consumo e perdas de capim-elefante (Pennisetum purpureum, Schum.) sob pastejo. 1987. 94f. Dissertação (Mestrado em Agronomia) Escola Superior de Agricultura Luiz de Queiroz /Universidade de São Paulo, Piracicaba.

KUNKLE, W.E.; BATES, D.B. Evaluating feed purchasing options: Energy, protein, and mineral supplements. Proceedings of the Florida Beef Cattle Short Course. Gainesville: 1998. p.59-70.

LIMA, M.L.P.; BERCHIELLI, T.T.; LEME, P.R. et al. Concentração de nitrogênio uréico plasmático (nup) e produção de leite de vacas mestiças mantidas em gramíneas tropicais sob pastejo rotacionado. Revista Brasileira de Zootecnia, v.33, n.6, p.1616-1626, 2004.

LOPES, R.S.; FONSECA, D.M; OLIVEIRA, R.A. et al. Efeito da irrigação e adubação na disponibilidade e composição bromatológica da massa seca de lâminas foliares de capim-elefante. Revista Brasileira de Zootecnia, v.34, n.1, p.20-29, 2005.

MISSIO, R.; BRONDANI, I.L. ; MENEZES, L.F.G. et al. Massa de lâminas foliares nas características produtivas e qualitativas da pastagem de capim-elefante "Pennisetum purpureum, Schum" (cv. "Taiwan”) e desempenho animal. Ciência Rural, v.36, n.4, p.1243-1248, 2006.

MORENO, J.A. Clima do Rio Grande do Sul. Porto Alegre: Secretaria da Agricultura, 1961. 41p.

NATIONAL RESEARCH COUNCIL - NRC. Nutrient requirements of dairy cattle. 6.ed. Washington: National Academy of Sciences, 1989. 157p.

OLIVO, C.J.; SOBCZACK, M.F.; CHARÃO, P.S. et al. Evaluation of an elephant grass pasture, managed under agroecology principles, during the summer period. Livestock Research for Rural Development, v.18, n.2, 2006. Disponível em: $<$ http://www.cipav.org.co/lrrd>. Acesso em: 20 maio 2010.

OLIVO, C.J.; ZIECH, M.F.; BOTH, J.F. et al. Produção de forragem e carga animal em pastagens de capim-elefante consorciadas com azevém, espécies de crescimento espontâneo e trevobranco ou amendoim forrageiro. Revista Brasileira de Zootecnia, v.38, n.1, p.27-33, 2009.

PACIULLO, D.S.C. Morfogênese e acúmulo de biomassa foliar em pastagem de capim-elefante avaliada em diferentes épocas do ano. Pesquisa Agropecuária Brasileira, v.38, n.7, p.881-887, 2003.

PEGORARO, R.F.; MISTURA, C.; WENDLING, B. et al. Manejo da água e do nitrogênio em cultivo de capim-elefante. Ciência e Agrotencnologia, v.33, n.2, p.461-467, 2009.

POLI, C.H.E.C. Desenvolvimento morfológico, produção de forragem, proteína bruta e digestibilidade in vitro de cinco cultivares de capim-elefante (Pennisetum purpureum, Schum.). 1992. 148f. Dissertação (Mestrado em Agronomia) - Universidade Federal do Rio Grande do Sul, Porto Alegre.

RODRIGUES, P.H.M; ANDRADE, S.J.T; FERNANDES, T. et al. Valor nutritivo da silagem de capim-elefante cultivar Napier (Pennisetum purpureum, Schum.) inoculada com bactérias ácido-láticas. Acta Scientiarum, v.23, n.4, p.809-813, 2001

SAS INSTITUTE. SAS user's guide: statistics. Version 6.11. Cary, North Carolin: SAS Institute, 1997. 1187p.

SOARES, J.P.G.; BERCHIELLI, T.T.; AROEIRA L.J. M. et al. Estimativas de consumo do capim-elefante (Pennisetum purpureum Schum), fornecido picado para vacas lactantes utilizando a técnica do óxido crômico. Revista Brasileira de Zootecnia, v.33, n.3, p.811-820, 2004

TILLEY, J.M.A.; TERRY, R.A. A two-stage technique of the "in vitro" digestion of forage crop. Journal of the British Grassland Society, v.18, n.2, p.104-111, 1963.

TOWNSEND, C.R.; OLIVO, C.J.; RUVIARO, C.F. Desempenho de novilhas da raça Holandesa em cultivares de capim-elefante (Pennisetum purpureum Schum.). Ciência Rural, v.24, n.2, p.381-386, 1994.

VAN SOEST, P.J. Nutritional ecology of the ruminant. Ithaca, Cornel, 1994. 476p.

VAN SOEST, P.J.; ROBERTSON, J.B.; LEWIS, B.A. Methods for dietary fiber, neutral detergent fiber, and nonstarch polysaccharides in relation to animal nutrition. Journal of Dairy Science, v.74, n.1, p.3583-3597, 1991.

WILM, H.G.; COSTELO, O.F.; KLIPPLE, G.E. Estimating forage yield by the double sampling method. Journal of the American Society for Agriculture, v.36, n.1, p.194-203, 1944 